\title{
NEUE ANGABEN ÜBER DIE AWARISCHEN GRÄBER VON SZENTENDRE AUS DEM NACHLASS DES FLÓRIS RÓMER
}

\author{
PÉTER PROHÁSZKA
}

\author{
Archeologický ústav SAV Nitra \\ Akademická 2, SK-949 21 Nitra, Slowakei \\ prohaszkapeter@freemail.hu
}

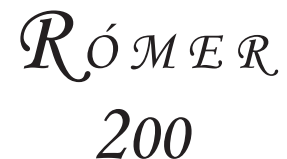

\begin{abstract}
This paper deals with the finding history and composition of the Avarian graves from Szentendre (County Pest, Hungary) based on literary data and new archival records. These records are in the legacy of the famous Hungarian archaeologist Flóris Rómer. They allow the reconstruction of the composition and the situation of the graves, which were found in 1871 on the ground of a brick factory. In the study drawings and notes of Flóris Rómer about finds and graves from Szentendre are published. They are important sources of the Avarian graves from the early Avarian age and the autor gives an evaluation on they in the study.
\end{abstract}

Keywords: archival records, Avars, Szentendre, graves, Flóris Rómer

Flóris Rómer beschäftigte sich mit den Denkmälern und archäologischen Funden zahlreicher Epochen, zu denen auch die Funde der Awarenzeit gehörten. ${ }^{1}$ Er berichtete über Schmuckstücke und Funde der Awarenzeit in den Zeitschriften Archaeologiai Értesitö und Archaeologiai Közlemények. In den Jahren seiner Tätigkeit am Ungarischen Nationalmuseum kamen einige Gräber zum Vorschein, die im Jahre 1874 - Dank der Münzbeigaben - zur chronologischen Bestimmung des awarischen Fundmaterials vom 6.-7. Jahrhundert führten. ${ }^{2}$ Diese Gräber wurden in Szentendre (Komitat Pest) und Ozora-Tótipuszta (Komitat Tolna) im August und Oktober 1871 angeschnitten, gestört und in der Folge freigelegt. ${ }^{3}$ Ihre Beigaben gelangten unter unklaren Umständen ins Ungarische Nationalmuseum. Obwohl Rómer als Leiter des Münz- und Antikenkabinettes bei der Rettung beider Bestattungen eine wichtige Rolle spielte, ${ }^{4}$ übernahm er die wissenschaftliche Bearbeitung und Veröffentlichung nicht. Er veröffentlichte nur einige kurze Berichte über die Grabbeigaben von Ozora-Tótipuszta in Tageszeitungen und publizierte die Korrespondenz in der Zeitschrift Archaeologiai Értesitö. ${ }^{5}$ Über die Funde von Szentendre verfasste er jedoch keinen Bericht für die Presse. Erst zwei Jahre später erwähnte er die Funde als Denkmäler der Völkerwanderungszeit im Führer der Museumsausstellung. ${ }^{6}$ Dies ist insofern bedauerlich, weil er die Funde sicherte und die Fläche um die Gräber ausgraben ließ. Der Grund für sein Schweigen könnte darin liegen, dass Franz Pulszky, Direktor des Nationalmuseums, diese wichtigen Funde bestimmen und bearbeiten wollte. ${ }^{7}$ Puls-

\footnotetext{
${ }^{1}$ Zur archäologischen Tätigkeit von Flóris Rómer: HAMPEL 1891 und BANNER 1958. Ein besonders großer Dank gebührt Herrn István Bardoly (Archiv des Gyula Forster Nationalen Zentrums für Erbschaftmanagement und Dienstleistung, Budapest), der die Forschungen des Verfassers mit seinen Ratschlägen und seiner Hilfe immer vorantrieb. Ich möchte des Weiteren Prof. Dr. Michael Schmauder für die sprachliche Korrektur des vorliegenden Textes danken. ${ }^{2}$ BÓNA 1982-1983, 81-82.

${ }^{3}$ Erste wissenschaftliche Veröffentlichung: BÓNA 1982 1983.
}

${ }^{4}$ Garam 2002.

${ }^{5}$ Pesti Napló 22 (1871) Nr. 239, 17. Oktober (Dienstag), 2; Pester Lloyd 1871, 18. Oktober, Nr. 242 (Mittwoch); Bisits 1872. Siehe dazu ausführlich: ProHÁSzKA 2012.

${ }^{6}$ RÓMER 1873, 29: „Hieher gehören noch die Überbleibsel des Sz.-Endrefundes (Pesth), nämlich die pyramidenartigen grossen goldenen Ohrgehänge, eisernen Steigbügel u. s. w." Die Funde von Szentendre waren im sechsten Schrank des zweiten Saales mit den Beigaben des awarischen Grabes von Kunágota ausgestellt. 
zkys Arbeit über die awarischen Funde Ungarns stellt jedoch keine wissenschaftliche Bearbeitung dar, weil er sich dabei hauptsächtlich mit der Münzdatierung beschäftigte und über die Fundumstände, -zusammensetzung usw. kaum Aussagen traf.

Die erste gründliche Bearbeitung erfolgte erst mehr als hundert Jahre nach der Auffindung durch István Bóna in seiner Abhandlung über die großen Awarenfunde des 19. Jahrhunderts. Bóna versuchte anhand der Literatur- bzw. Archivangaben die Fundumstände, die Zusammensetzung und die Geschichte der bedeutenden Awarenfunde - wie Kunágota, Szentendre, Ozora, Dunapentele usw. - zu rekonstruieren und so ein Fundament für die Awarenforschung zu schaffen. Bei diesem Vorhaben halfen ihm die Zeichnungen und Notizen Flóris Rómers in seinem Notizbuch auf den Seiten 113 und 118 bzw. die im Archiv des Münz- und Antikenkabinettes des Ungarischen Nationalmuseums verwahrten Akten. Trotz seiner gründlichen Arbeit blieben einige wichtige Quellen unbeachtet, die neue und wichtige Angaben zur Fundgeschichte der Awarenfunde von Szentendre bieten und die sich im Nachlass von Flóris Rómer im Archiv des Gyula Forster Nationalen Zentrums für Erbschaftmanagement und Dienstleistung befinden. ${ }^{8}$ Bónas Aufmerksamkeit entging auch ein Bericht über das erste Grab in der Tagespresse, der aber nicht aus der Feder Rómers stammte.

Bei der Rekonstruktion der Fundumstände und der Gräber führten manche falschen Interpretationen der schwer lesbaren, meistens in Deutsch geschriebenen, handschriftlichen Aufzeichnungen im Notizbuch Rómers zu verschiedentlichen Missverständnissen bei deren Lesung. Wegen dieser falsch gelesenen Angaben ist heute in Hinsicht auf die Beigaben bzw. die Lage der Gräber vieles zu revidieren, wobei insbesondere eine Notiz Rómers von besonderer Bedeutung ist. Aus dieser Notiz geht hervor, was Flóris Rómer in Bezug auf die Funde zwischen dem 18. und 28. August tat und veranlasste. ${ }^{9}$ Demnach erfuhr Rómer aus einem Zeitungsartikel vom 18. August darüber, dass in Szentendre ein reiches Grab mit goldenen Beigaben zum Vorschein gekommen war. ${ }^{10}$ Diese kurze Mitteilung befindet sich im Pester Lloyd, in der damals wichtigsten deutschsprachigen Zeitung, was der Forschung bisher vollkommen unbekannt war. Es heißt dort: ,[Ein interessanter archäologischer Fund] den wir der Beachtung unserer Archäologen empfehlen, ist kürzlich von den Arbeitern des Ziegelwerkunternehmens J. H. Wojaczek in NagyKör bei Szt.Endre gemacht worden. Man stieß nämlich beim Graben in den Lehmfeldern auf ein männliches Skelett, an dem sich Bruchstücke einer goldenen Krone, ein goldener Ring, Bestandtheile einer Waffenrüstung bestanden; daneben das Gerippe eines Streitrosses mit Sattel und Steigbügeln und eines großen Jagdhundes. Auch mehrere alte Goldmünzen wurden in der Nähe gefunden. Die Grabungen werden fortgesetzt und fördern noch immer neue Gegenstände zu Tag. Herr Wojaczek wird seinerzeit das Ergebniß derselben der Regierung einsenden, ist aber auch jetzt schon bereit, Sachverständigen seinen Fund zu zeigen. ${ }^{\text {“11 }}$ Darüber hinaus übernahm die Tageszeitung A Hon, wenn auch etwas gekürzt, diese Nachricht ein Tag später. ${ }^{12}$

Aufgrund der Nachricht fuhr Rómer am 18. August 1871 (Freitag) zur Ziegelfabrik nach Szentendre, was er auch in seinem Notizbuch vermerkte. ${ }^{13}$ Dort notierte er gleichfalls seine Beobachtungen zu den Gräbern und

${ }^{7}$ Bóna 1982-1983, 129, Anm. 19: „A leletekre minden bizonnyal föigazgatója, Pulszky Ferenc tartott igényt - úgy is fogalmazhatnánk, hogy Ozora-Pusztatótival együtt elvette Rómertől a szentendrei leleteket is. Mentsége, hogy jól felhasználta őket.“

${ }^{8}$ BÓNA 1982-1983, 129, Anm. 19: „Rómer helyszíni feljegyzései azonban feledésbe merültek, kivált azok a megfigyelések, amelyeket fel sem jegyzett." Bónas Anmerkung, nachdem die Aufzeichnungen und Notizen Rómers in Vergessenheit gerieten bzw. gar nicht erstellt wurden, müssen wir gerade angesichts der sich im Nachlass befindenden Aufzeichnungen bestreiten. Im Archiv des Gyula Forster Nationalen Zentrums für Erbschaftmanagement und Dienstleistung (Budapest), Nachlass Rómer K 505/100-105 befinden sich folgende Notizen und Zeichnungen: 100: Revers der Funde vom 22. August 1871; 101: Zeichung des Löffels mit den Anmerkungen Rómers; 102: Zeichnung der aufgegrabenen Fläche mit den Positionen der Gräber; 103: Kalkulationen über die zu zahlenden Summen wegen der Ausgrabung; 104: Notiz Rómers mit seinem Programm zwischen dem 21. und 28. August 1871. Neben diesen befinden sich im Nachlass noch zwei Briefe über die Ausgaben der Ausgrabung: K 505/122-123.
${ }^{9}$ Archiv des Gyula Forster Nationalen Zentrums für Erbschaftmanagement und Dienstleistung (Budapest), Nachlass Rómer K 505/104.

${ }^{10}$ Archiv des Gyula Forster Nationalen Zentrums für Erbschaftmanagement und Dienstleistung (Budapest), Nachlass Rómer K 505/104: „Aug. 18. Hirlap cikk, Hegedüs Ő Mga Sz. Endrén kimentem a téglavetőből." [18. August. Zeitungsartikel, Hvgr. Hegedüs in Szentendre, ich ging aus der Ziegelfabrik heraus.]

${ }^{11}$ Pester Lloyd 1871, Nr. 191, 18. August.

${ }^{12}$ A Hon 9 (1871) Nr. 190, 19. August, 2: „Különfélék. Talált régiségek. Sz. Endre mellett Nagy-Körön téglagyárat építenek. Az ottani ásatások alkalmával az agyag földben egy férficsontvázra akadtak, fején egy koronatöredékkel, ujján aranygyürüvel. Mellette fegyverzet maradványok is találtattak, azonfelül egy harczi mén csontváza nyereggel és kengyellel s egy vadászeb csontváza. Több régi érmet is leltek a munkálatok folytán, uj meg uj (azaz, hogy régi) tárgyakat hoznak napvilágra." Etwas verkürzt wurde auch diese Meldung in Vasmegyei Lapok 5 (1871) Nr. 68, am 27. August (S. 2) veröffentlicht.

${ }^{13}$ Archiv des Gyula Forster Nationalen Zentrums für Erbschaftmanagement und Dienstleistung (Budapest), Nachlass Rómer, Notizbuch Nr. 33, S. 115: Freitag 18ten Ziegelei Fiaker 7 ft. 


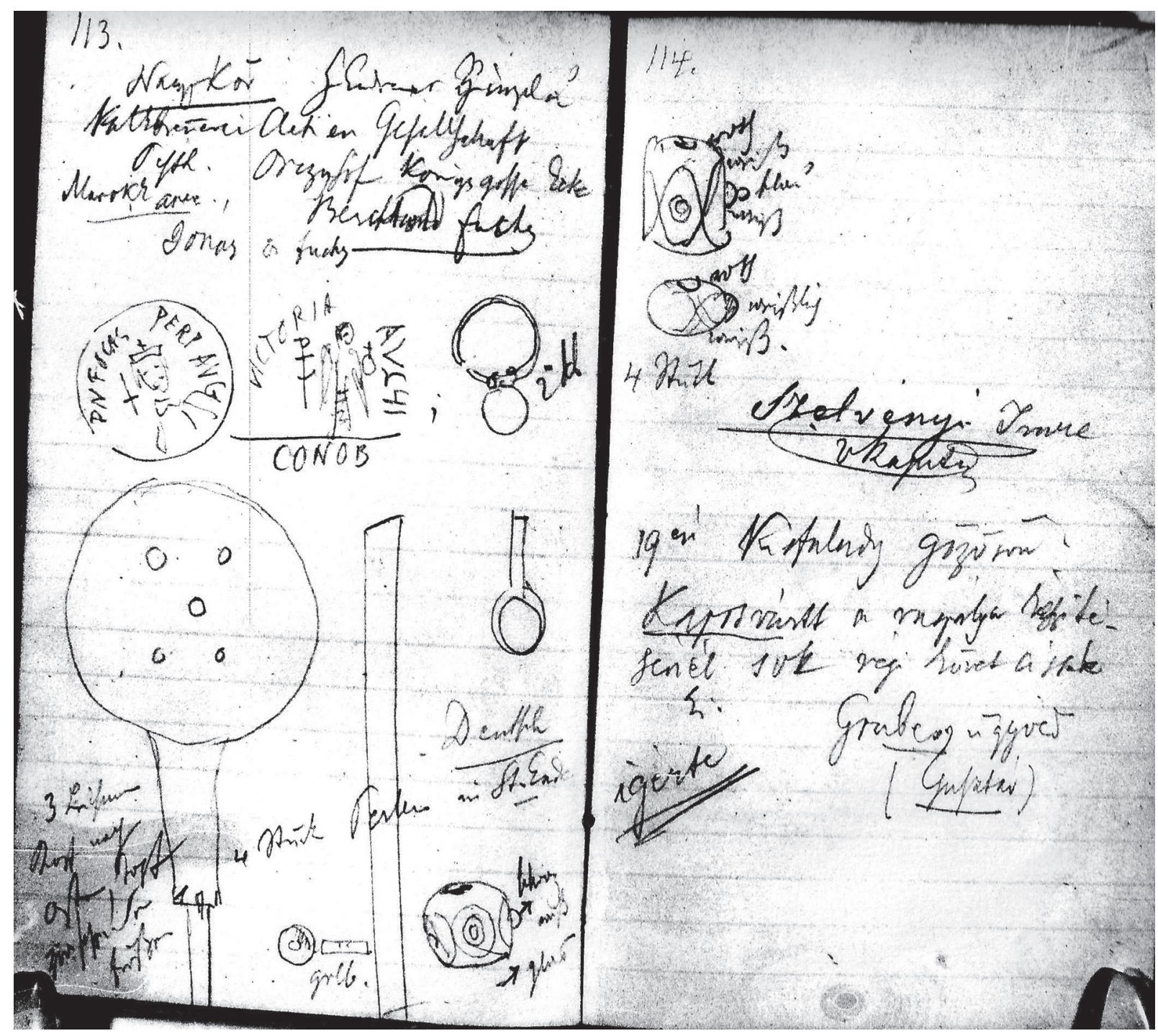

Abb. 1. Zeichnungen und Aufzeichnungen Rómers über die Gräber von Szentendre (Gyula Forster Nationales Zentrum für Erbschaftsmanagement und Dienstleistung, Budapest)

zeichnete die geretteten Beigaben des dritten Grabes (Abb. 1). ${ }^{14}$ Auf zwei Seiten sind die Beigaben abgebildet: Solidus des Phokas, kleines Ohrgehänge mit Kugelanhänger, Silberlöffel und vier Perlentypen. An dieser Stelle muss darauf hingewiesen werden, dass zum Fund nie ein silbernes Messer bzw. ein Messergriff gehörte. Die Zuordnung basierte auf einem Missverständnis. ${ }^{15}$ Rómer zeichnete den Silberlöffel nämlich in drei Teilen: Kopf, Griff und Ende. Aus der Zeichnung des Griffes wurde der Messergriff, der aber nie existierte. Besonders wichtig sind die Anmerkungen Rómers über die Ziegelei und ihren Besitzer: „Nagykör SzEndreer Ziegel u Kalkbrenerei Actien Gesellschaft Pesth. Orczyhof Konigsgasse Ecke Marokkaner. Berthold Fuchs. Jonás \& Fuchs. "16 Am Seitenende weist er auf die Gräber hin: „3 Leichen Kopf nach Osten, Topf zwischen den Füßen.“17 Über die Perlen heißt es:

${ }^{14}$ Archiv des Gyula Forster Nationalen Zentrums für Erbschaftmanagement und Dienstleistung (Budapest), Nachlass Rómer, Notizbuch Nr. 33, S. 113-117; siehe auch: MRT 5, 291.

${ }^{15}$ Er wird als Grabbeigabe behandelt: BóNA 1982-1983, 99; GARAM 1993, 31; SCHMAUdER 2005, 243.
${ }^{16}$ Archiv des Gyula Forster Nationalen Zentrums für Erbschaftmanagement und Dienstleistung (Budapest), Nachlass Rómer, Notizbuch Nr. 33, S. 113.

${ }^{17}$ Archiv des Gyula Forster Nationalen Zentrums für Erbschaftmanagement und Dienstleistung (Budapest), Nachlass Rómer, Notizbuch Nr. 33, S. 113. 
„Deutsch 4 Stück Perlen in Szentendre.“18 Wegen der fehlerhaften Lesung der Handschrift Rómers entstanden, wie bereits erwähnt, manche Irrtümer in der Abhandlung von István Bóna. So las er statt „Deutsch“ Deuther (nach Bóna: zweite), seiner Meinung nach wollte Rómer also auf ähnliche Perlen im zweiten Grab anspielen, von denen drei Stück eingeliefert wurden (Liefern) und einige zerfielen (Zerf.). Rómer wies hier jedoch auf die Gräber hin: „3 Leichen Kopf nach Osten, Topf zwischen den Füßen.“19

Rómer zeichnete vier Perlentypen in seinem Notizbuch: $:^{20}$ eine runde, flache kleine gelbe Perle, eine mittlere Augenperle mit schwarzer und weißer sowie glatter Verzierung. Oben auf der nächsten Seite ist die Zeichnung einer langen Augenperle mit „roth(em), weiß(em), blau(em) und weiß(em)“ Muster, darunter eine flachere mit „roth(em), weißlich(em) und weiß(em)“ Muster abgebildet. Von dem letztgenannten Typ gab es vier Stück (4 Stück). ${ }^{21}$ Vielleicht an diesem Tag oder in den nächsten Tagen machte Rómer Notizen über die aufgefundenen Gräber. Er zeichnete unter anderem einen Ziegel mit Stempel - Sz.E (ungarisches Wappen mit Krone) RT [SzentEndrei Részv. Társaság - Szentendreer Aktiengesellschaft], H-W [Heinrich Wojaczek] -, der fast hundert Jahre später bei der Lokalisierung der Fundstelle half. ${ }^{22}$ Aufgrund des Vorkommens von Ziegeln mit entsprechenden Stempeln könnte sich die Fundstelle 200 m nördlich von der Pannonia Ziegelei, 150-200 m westlich der Donau und 800-900 m südlich von der Mündung des Dera-Baches befunden haben. ${ }^{23}$

Unter der Zeichnung des Ziegelstempels findet man folgende Anmerkung Rómers: ${ }^{24}$,... zwischen 7 u 8 Schopfe in der Mitte 5' unter der Erde Knochen, ein Grube 2.60 centim. Breit. “25 Auf der nächsten Seite ergänzte er diese Angaben wie folgt: ${ }^{26}$, ,SzEndren 1. és 2. Schopfen irányában aranyos ember fazék a másik északnyugatra fekvő embernél.“ " [In Szentendre in der Richtung der 1. und 2. Schopfen ein goldener Mann, ein Topf beim anderen, nordwestlich liegenden Mensch]. Es ist fraglich, ob dieser Topf mit dem gelblichen groben Henkelkrug identisch ist, der als Geschenk des Ziegeleibesitzers Jónás ins Nationalmuseum gelangte. ${ }^{27}$ Leider wurden auch diese Zeilen Rómers falsch gelesen, was zu manchen Missverständnissen führte. Hier kommt zum Beispiel bei der Grabtiefe statt 5' (Fuß) $260 \mathrm{~cm}$ vor, womit jedoch die Grabbreite angegeben wurde. ${ }^{28}$ Anhand der Skizze und der Beigaben war das Grab des „,goldenen Menschen“ die Männerbestattung mit Waffenbeigabe, also das Grab 1. Diese Anmerkungen Rómers sind unter Berücksichtigung jener Skizze möglich, die sich in seinem Nachlass befindet (Abb. 2). ${ }^{29}$ Auf dieser Skizze sind die Maßen der ausgegrabenen Fläche mit der Lage der Gräber angegeben. Er notierte die Breite der großen Grabgrube mit der folgenden Anmerkung: „Cadave“. ${ }^{30}$ Die Fläche wurde $25^{\circ}$ (Klafter) lang und $6^{\circ}$ (Klafter) breit aufgegraben. ${ }^{31}$ Nach der Beschreibung kam 10-12 m westlich vom großen Grab die erste Frauenbestattung und die zweite ungefähr 50 m nordwestlich davon zum Vorschein. Rómer ließ die Fläche zwischen den Gräbern ausgraben, was von dem am 23. August angekommenen Geld des Ministeriums bezahlt wurde.

Rómer reiste am Wochenende nach Balatonfüred und erst am 21. August (Montag) fuhr er wieder zur Ziegelfabrik hinaus. ${ }^{32}$ Aber nach seinem Notizbuch begann er diesen Tag in Pomáz. Über das, was er dort tat, stehen uns keine Angaben zur Verfügung. Daher ist es auch fraglich, ob sich die Beigaben des ersten oder eines anderen

${ }^{18}$ Archiv des Gyula Forster Nationalen Zentrums für Erbschaftmanagement und Dienstleistung (Budapest), Nachlass Rómer, Notizbuch Nr. 33, S. 113.

${ }^{19}$ BÓNA 1982-1983, 99; vgl. das Archiv des Gyula Forster Nationalen Zentrums für Erbschaftmanagement und Dienstleistung (Budapest), Nachlass Rómer, Notizbuch Nr. 33, S. 113.

${ }^{20}$ Zur Identifizierung der Perlen siehe: BóNA 1982-1983, 99.

${ }^{21}$ Archiv des Gyula Forster Nationalen Zentrums für Erbschaftmanagement und Dienstleistung (Budapest), Nachlass Rómer, Notizbuch Nr. 33, S. 114.

${ }^{22}$ Archiv des Gyula Forster Nationalen Zentrums für Erbschaftmanagement und Dienstleistung (Budapest), Nachlass Rómer, Notizbuch Nr. 33, S. 116.

${ }^{23}$ MRT 5, 291; vgl. BÓNA 1982-1983, 98.

${ }^{24}$ Archiv des Gyula Forster Nationalen Zentrums für Erbschaftmanagement und Dienstleistung (Budapest), Nachlass Rómer, Notizbuch Nr. 33, S. 116. Bei der Zusammenstellung der archäologischen Topographie konnten die Autoren diese Zeilen Rómers nicht verstehen oder eher lesen: MRT 5, 291. István Bóna las es als „Knochen in Grube": BÓNA 1982-1983, 98

${ }^{25}$ BÓNA 1982-1983, 98.
${ }^{26}$ Archiv des Gyula Forster Nationalen Zentrums für Erbschaftmanagement und Dienstleistung (Budapest), Nachlass Rómer, Notizbuch Nr. 33, S. 117.

${ }^{27}$ Ungarisches Nationalmuseum (Budapest), Münz- und Antikenkabinett 284/1871; MRT 5, 291-292. Das Gefäß ist abhanden gekommen.

${ }^{28}$ BÓNA 1982-1983, 98

${ }^{29}$ Archiv des Gyula Forster Nationalen Zentrums für Erbschaftmanagement und Dienstleistung (Budapest), Nachlass Rómer K 505/102.

${ }^{30}$ Diese Zeichnung und Rechnungen beziehen sich auf jenen Entwurf, den Rómer in seinem Konzept an das Ministerium erwähnte: Ungarisches Nationalmuseum (Budapest), Archiv des Münz- und Antikenkabinettes, 1870-1872, ohne Inventarnummer.

${ }^{31}$ Unter der Zeichnung steht: „Bei Abgrabungen von $25^{\circ}$ länge $6^{\circ}$ breite d. $1^{\circ}-4$ ' tiefe somit 250 Cub Klafter á f. $4 .=$ f. 1000 sollte die Tiefe um 2 Fuß vermehrt, dann ist das Cubikmaß auf 250 Cub Klaft a f. 4 = 1100-."

${ }^{32}$ Archiv des Gyula Forster Nationalen Zentrums für Erbschaftmanagement und Dienstleistung (Budapest), Nachlass Rómer K $505 / 104$ 


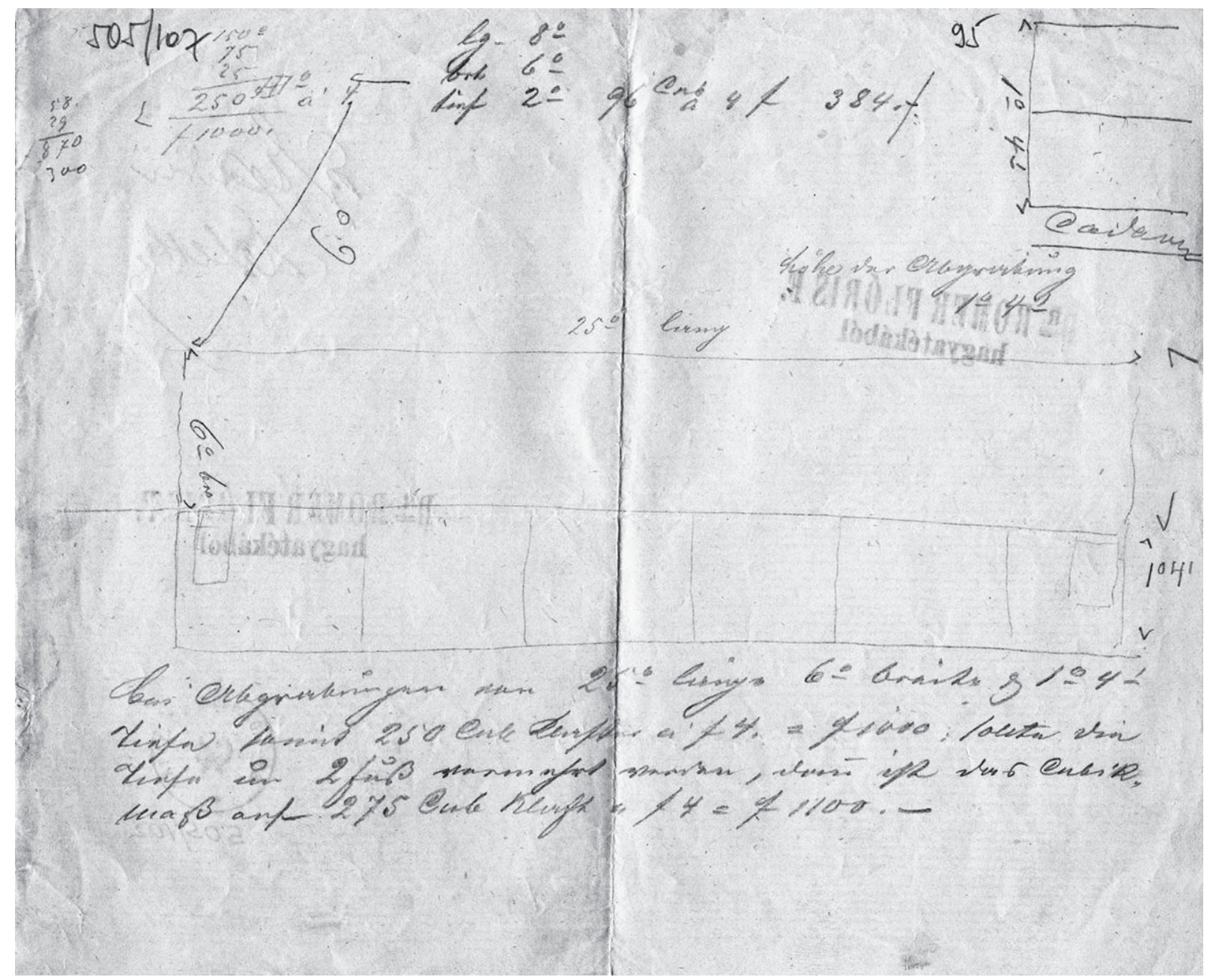

Abb. 2. Die Lage der Gräber von Szentendre (Gyula Forster Nationales Zentrum für Erbschaftsmanagement und Dienstleistung, Budapest)

Grabes bei dem Kreisrichter in Pomáz befanden. ${ }^{33}$ Höchstwahrscheinlich waren die Funde schon in seinem Besitz, was durch die Tatsache untermauert wird, dass er am 22. August (Dienstag) zur Ziegelei fuhr und nach Aussage des Revers - einer Übergabequittung - in seinem Nachlass die gesammelten Gegenstände den Ziegeleibesitzern übergeben musste. ${ }^{34}$ Inzwischen konnte er jedoch erreichen, dass ihm das Ministerium 1700 Forint für die Ausgrabung zuwies. Er erhielt den Betrag am 23. August (Mittwoch). Rómer fuhr jedoch zunächst mit Gusztáv Zsigmondy nach Altofen und erschien erst wieder am 24. August (Donnerstag) am Fundort. Am 25. August (Freitag) sprach er mit den Herren Fuchs und Jónás sowie am 27. August (Sonntag) mit Herrn Wojaczek. ${ }^{35}$

${ }^{33}$ BÓNA 1982-1983, 98. Ebenfalls unklar ist die Rolle des Stadthauptmanns Imre Szebrenyi (in Wirklichkeit Szelvényi), dessen Name im Notizbuch vermerkt wurde, der aber in keinem anderen Kontext auftaucht. Höchstwahrscheinlich bat Rómer ihn, die Panduren zu bestellen, die den Fundort bewachten, worauf Wojaczek in seinem Brief vom 15. September hinweist: Archiv des Gyula Forster Nationalen Zentrums für Erbschaftmanagement und Dienstleistung (Budapest), Nachlass Rómer K 505/122.
${ }^{34}$ Archiv des Gyula Forster Nationalen Zentrums für Erbschaftmanagement und Dienstleistung (Budapest), Nachlass Rómer K 505/100. Nach Aussage dieser Quittung waren die Beigaben des ,goldenen Mannes“ am 23. August gewiss nicht bei dem Stadthauptmann Szebrenyi (Szelvényi): BóNA 1982-1983, 98.

${ }^{35}$ Archiv des Gyula Forster Nationalen Zentrums für Erbschaftmanagement und Dienstleistung (Budapest), Nachlass Rómer K 505/104; vgl. BóNA 1982-1983, 98. Die neu gefundenen Dokumente widersprechen der in seinem Beitrag dargestellten Ereigniskette. 
Wie bereits erwähnt, musste Rómer die gesammelten Funde am 22. August wegen des Anspruchs des Besitzers herausgeben, wie dies ein Revers mit der Auflistung der Funde in seinem Nachlass belegt. Dieser Revers hilft nicht nur bei der Identifizierung eines Fundes, sondern führt auch eine bisher unbekannte Beigabe an. ${ }^{36}$

\section{Revers}

über folgende mir anvertraute, zu Sz. Endre auf der Ziegelei der Herrn Jonas \& Fuchs gefundenen Gegenstände 2 Stück goldene große Ohrringe ohne Einhängeringe

1 dazu gehörige Goldperle

2 Stück goldene größere Ohrringe mit je 4 Goldperlen besetzt

2 Stück goldene Ohrringe ähnlich, aber kleiner

1 Stück goldener Ring mit 4 Goldperlen besetzt, Stein fehlt

1 Stück Goldring mit kleinen Goldperlen besetzt

1 Stück Münze von Kaiser Justinus \#

1 Stück FOCAS \#

4 Stück Silber von 2 Braceletten, hornförmig

2 Stück Säbelscheide-Besätze, eines gebrochen

17 Stück Thonperlen

2 eiserne Steigbügel

1 eiserne Lanzenspitze.

Ich verpflichte mich auf Verlangen diese Gegenstände von Herren Eigenthümern auszufolgen.

Pesth im Nationalmuseum den 22/Aug. 871.

Dr. Florian Romer

Kön. Rath, Conservator des AntikeCabinette

Die Funde gelangten aber erst fast zwei Monate später wieder ins Nationalmuseum, nachdem sie für 100 Forint am 25. Oktober 1871 gekauft worden waren ${ }^{37}$ Inzwischen brachten die Ausgrabungen Rómers, die zwölf Tage lang dauerten ${ }^{38}$ keine neuen Funde bzw. Gräber zum Vorschein. ${ }^{39}$ Ihre Inventarisierung, die in der Folge zu manchen Problemen bei der Bestimmung führte, geschah schon am folgenden Tag. So wurde das silberne Kolbenarmringpaar als Silberschmuck inventarisiert, ${ }^{40}$ obwohl es im Revers von Rómer als Armringe (Braceletten) beschrieben wurde, die in vier Stücke zerbrochen war. ${ }^{41}$ Während ein Teil der Funde - wie die Münzen, Speerspitze, Steigbügel und Armringe - mit den Literaturangaben übereinstimmt, ist eine Abweichung bei den Fingerringen zu bemerken. Im Revers werden die Ohrringe zutreffend genannt. Es wird sogar eine abgebrochene Perlenverzierung des einen Ohrgehänges mit großem pyramidenförmigem Anhänger angeführt, die ebenfalls ins Nationalmuseum gelangte. ${ }^{42}$ Im Revers verweist Rómer nicht eigens auf die abgebrochenen Ringe, die als eigenständige Objekte inventarisiert wurden und höchstwahrscheinlich noch an den Ohrringen angebracht waren. ${ }^{43}$

${ }^{36}$ Archiv des Gyula Forster Nationalen Zentrums für Erbschaftmanagement und Dienstleistung (Budapest), Nachlass Rómer K $505 / 100$.

${ }^{37}$ Ungarisches Nationalmuseum (Budapest), Inventarbuch des Münz- und Antikenkabinettes: 288/1871. „Ezen tárgyak a téglavető és mészégető társulattól vétettek. Október 25én 1871100 o.é.“ [Diese Gegenstände sind von der Ziegelbrenner und Kalkbrenner Gesellschaft gekauft worden. Am 25. Oktober 1871, für $100 \mathrm{ft}$.] Rómer kaufte sie nicht aus dem Grabungsgeld, sondern aus dem Budget des Nationalmuseums; vgl. BóNA 1982-1983, 98.

${ }^{38}$ Archiv des Gyula Forster Nationalen Zentrums für Erbschaftmanagement und Dienstleistung (Budapest), Nachlass Rómer K $505 / 103$.
${ }^{39}$ Ungarisches Nationalmuseum (Budapest), Archiv des Münz- und Antikenkabinettes 1870-1872, ohne Inventarnummer; vgl. BÓNA 1982-1983, 98.

${ }^{40}$ Ungarisches Nationalmuseum (Budapest), Inventarbuch des Münz- und Antikenkabinettes: 288/1871.III.1; vgl. MRT 5, 290-291.

${ }^{41}$ Archiv des Gyula Forster Nationalen Zentrums für Erbschaftmanagement und Dienstleistung (Budapest), Nachlass Rómer K $505 / 100$.

${ }^{42}$ Ungarisches Nationalmuseum (Budapest), Inventarbuch des Münz- und Antikenkabinettes: 266/1871.II.6.

${ }^{43}$ Ungarisches Nationalmuseum (Budapest), Inventarbuch des Münz- und Antikenkabinettes: 266/1871.II.5. Die Darstellung der Fingerringe siehe: BóNA 1982-1983, 100. 
Viel interessanter ist jedoch die Frage nach den Fingerringen. Während der ,goldene Ring mit 4 Goldperlen besetzt, Stein fehlt" mit dem Ring aus dem ersten Grab gut identifizierbar ist, liegt von dem anderen nur die kurze Beschreibung des Revers - „Goldring mit kleinen Goldperlen besetzt“ - vor. Es wäre plausibel, den perlenverzierten Ring des Ohrgehänges mit großem Kugelanhänger mit diesem Goldring zu identifizieren, aber die Ringe dieses Ohrgehängepaares waren nicht abgebrochen. Daher wurde die Möglichkeit ins Auge gefasst, dass es sich im ersten Grab noch ein Fingerring befanden haben sollte. Diese Annahme stützt sich auf einen mit rautenförmigem Kopf verzierten, fast identischen Fingerring des ersten Grabes, der 1874 vom Antiquitätenhändler Krausz für das Nationalmuseum gekauft wurde. ${ }^{44}$ Rómer sah aber einen anderen Typ und so wies er auf die Übereinstimmung mit den anderen nicht hin. Er vermerkte nur kurz, dass Ersterer mit kleinen Goldperlen verziert war. Dieser Fingerring - wie der Silberlöffel und die größere Perle - gelangte schließlich nicht ins Nationalmuseum. Dank des Revers ist es möglich, die im Inventarbuch beschriebenen und heute nicht mehr auffindbaren silbernen Schließenbruchstücke zu bestimmen. ${ }^{45}$ Diese wurden für Bruchstücke eines Silberlöffels ${ }^{46}$ oder eines von Rómer nicht erkannten dritten Armringes gehalten. ${ }^{47}$ Es wurde sogar angenommen, dass es sich um Bruchstücke eines silbernen Pferdegeschirrs handeln würde. ${ }^{48}$ Nach Aussage des Revers waren die beiden silbernen Schließen Säbelscheidebesätze des Schwertes aus dem ersten Grab.

Merkwürdig ist darüber hinaus, was im Zeitungsbericht als Krone erwähnt wurde. Höchstwahrscheinlich wurden die beiden goldenen Ohrringe so benannt, weil man sich seinerzeit nicht vorstellten konnte, dass sich entsprechende Schmuckstücke in Waffengräbern befinden könnten. ${ }^{49}$

Wie bereits erwähnt, dauerte die Ausgrabung der Fläche zwischen den Gräbern zwölf Tage und war schließlich erfolglos. ${ }^{50}$ Neue Funde wurden damals nicht geborgen. Während der Arbeiten in der Ziegelfabrik, wie aus dem Bericht Rómers an das Ministerium hervorgeht, kamen wieder zahlreiche Gräber mit Menschen- und Pferdegerippen zum Vorschein. ${ }^{51}$ Diese Gräber gehörten aber sicher zu einem anderen awarischen Gräberfeld, ${ }^{52}$ über das sich weder ein Brief noch eine Aufzeichnung im Nachlass Rómers findet.

Die erste Rekonstruktion der Gräber von Szentendre und ihrer Beigaben nahm, wie eingangs erwähnt, István Bóna vor, ${ }^{53}$ weil man früher auf die Zahl der Gräber nur folgern konnte. Seine Ergebnisse wurden sowohl in Ungarn ${ }^{54}$ als auch im Ausland akzeptiert. ${ }^{55}$ Anhand der Aufzeichnungen, Notizen und Zeichnungen Rómers sowie der Angaben des Inventarbuchs ist über die Gräber von Szentendre und ihre Beigaben gesichert nun Folgendes bekannt.

Grab 1 (Abb. 3.a). Männergrab mit Pferd und Hund, Kopf nach Osten. Tiefe fünf Fuß (ungefähr $150 \mathrm{~cm}$ ), Breite der Grabgrube ungefähr $260 \mathrm{~cm}$. Beigaben: a) goldener Fingerring mit rautenförmigem Kopf, ${ }^{56}$ b) goldenes filigranverziertes Ohrgehängepaar mit großem Kugelanhänger, c) eiserne Speerspitze, d) Steigbügelpaar mit langer Öse, e) silberne Säbelscheidenbesätze. ${ }^{57}$

Grab 2 (Abb. 3.b). Frauengrab, Kopf nach Osten. Beigaben: a) goldenes Ohrgehängepaar mit großem pyramidenförmigem Anhänger, b) silbernes Kolbenarmringpaar, c) Halskette aus Perlen, ${ }^{58}$ d) höchstwahrscheinlich in diesem Grab befand sich der Tremisses des Justinus II., e) Keramikgefäß (?). ${ }^{59}$

\footnotetext{
${ }^{44}$ Ungarisches Nationalmuseum (Budapest), Inventarbuch des Münz- und Antikenkabinettes: 88/1874.2; vgl. GARAM 1993, 31.

${ }^{45}$ Ungarisches Nationalmuseum (Budapest), Inventarbuch des Münz- und Antikenkabinettes: 288/1871.III.2; vgl. MRT 5, 290 und 292. Diese Gegenstände kommen in keiner Bearbeitung vor.

${ }^{46}$ BÓNA 1982-1983, 99.

${ }^{47}$ MRT 5, 290.

${ }^{48}$ BÓNA 1982-1983, 99-100.

${ }^{49}$ BÓNA 1982-1983, 99.

${ }^{50}$ Archiv des Gyula Forster Nationalen Zentrums für Erbschaftmanagement und Dienstleistung (Budapest), Nachlass Rómer K $505 / 103$.

${ }^{51}$ MRT 5, 291.

${ }^{52}$ BÓNA 1982-1983, 99.

${ }^{53}$ BÓNA 1982-1983, 98-104, bes. 100.

${ }^{54}$ Garam 1993, 31. Die Zeichnung der Funde: Garam 1992, 214-216, Taf. 89-91.

${ }^{55}$ SCHMAUDER 2005, 243.
}

\begin{abstract}
${ }^{56}$ Die Annahme, dass es sich im ersten Grab noch ein Fingerring befand, wird durch keinerlei Angabe untermauert. Der Bericht in Pester Lloyd erwähnt gleichfalls nur einen. So kann man den von dem Antiquitätenhändler gekauften Fingerring trotz seiner Formverwandtschaft mit dem anderen Fingerring nicht als Beigabe des ersten Grabes betrachten. Siehe: GARAM 1993, 31.

${ }^{57}$ In einem der zwei Gräber befand sich der im Revers genannte Goldring.

${ }^{58}$ Im Katalog von É. Garam (GARAm 1993, 105) werden noch andere Perlen anhand des Inventarbuchs angeführt: „,11 St bunte Augenperlen, 8 St kugelförmige grüne, gelbe und ziegelfarbige Perlen und 2 St gelbe, zusammengesetzte Glasperlen.“

${ }^{59}$ I. Bóna und M. Schmauder meinten, dass das Gefäß im dritten Grab war (BóNA 1982-1983, 98; SCHMAUDER 2005, 243). Wenn dies jedoch so gewesen wäre, hätte Rómer es sicher erwähnt und gemeinsam mit den anderen Beigaben des Grabes gezeichnet.
\end{abstract}



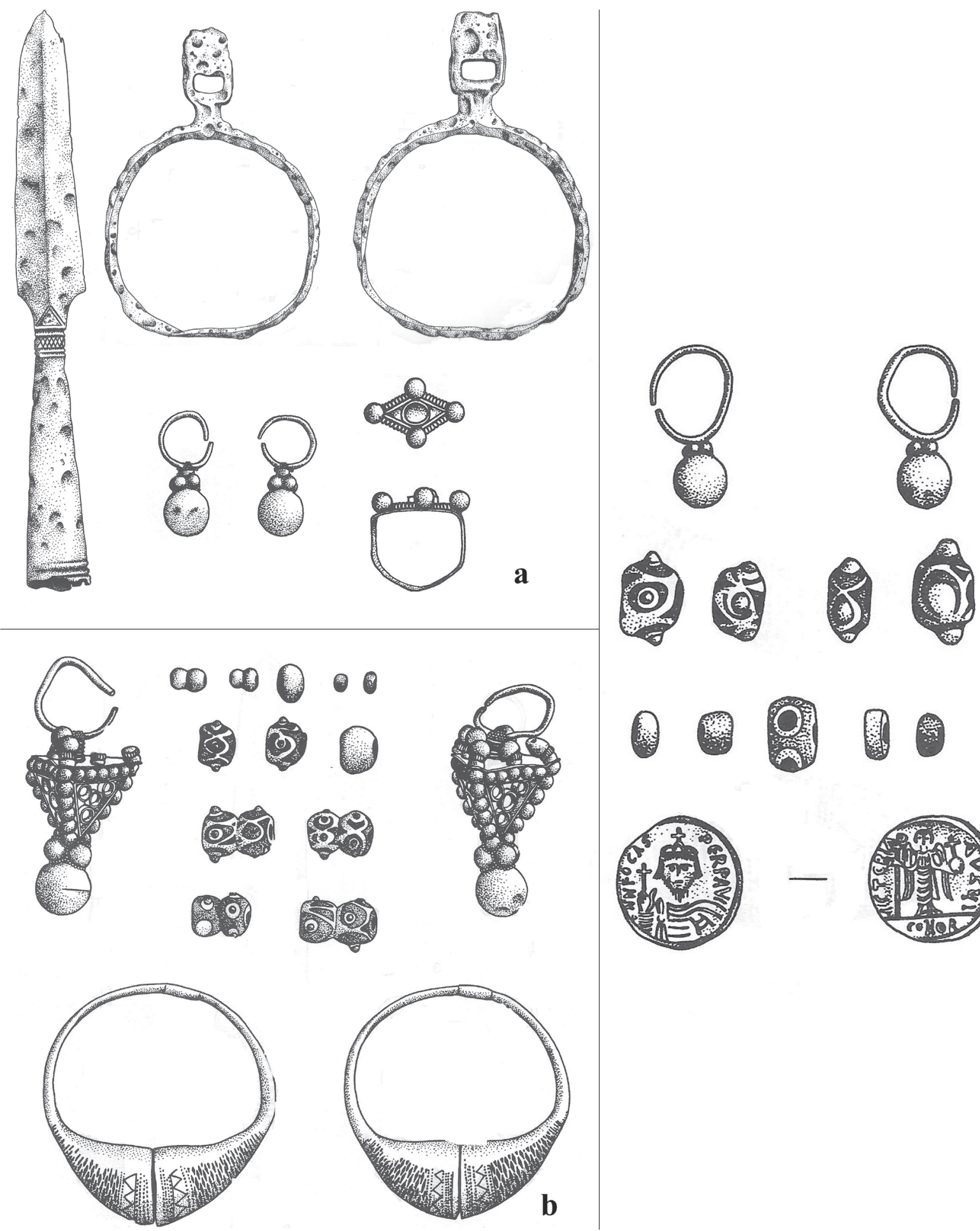

Abb. 3. Die Beigaben der Gräber von Szentendre. a: Grab 1; b: Grab 2; c: Grab 3 
Grab 3 (Abb. 3.c). Frauengrab, Kopf nach Osten. Beigaben: a) goldenes filigranverziertes Ohrgehängepaar mit kleinem Kugelanhänger, b) Solidus des Phokas, c) Silberlöffel, d) Halskette aus Perlen (eine kleine scheibenförmige gelbe, eine größere schwarz-gelbe Perle, eine kugelige Augenperle, eine flachere Augenperle, eine größere zylindrische Perle). ${ }^{60}$

Dank der Aufzeichnungen und Zeichnungen, die sich im Nachlass von Flóris Rómer befinden, konnte die Fundgeschichte der awarischen Gräber von Szentendre durch neue Angaben ergänzt werden.

\section{LITERATUR}

BANNER 1958

BISITS 1872

BÓNA 1982-1983

DAIM 2003a

DAIM 2003b

GARAM 1992

GARAM 1993

GARAM 2002

HAMPEL 1889

HAMPEL 1891

HAMPEL 1905

MRT 5

ProHÁSZKA 2012

PULSZKY 1874

PuLSZKY 1897

RÓMER 1871a

RÓMER 1871b

RÓMER 1872a

RÓMER 1872b

RÓMER 1873

SCHMAUDER 2005

SZENDREI 1888
= J. BANNER: Rómer Flóris emlékezete (Erinnerung an Flóris Rómer). Régészeti Dolgozatok 1 (1958) $1-21$.

= M. BIsıTs: Ozorai leletekről (Über die Funde von Ozora). Archaeologiai Értesítő 6 (1872) 16-17.

= I. BóNA: A XIX. század nagy avar leletei (Die großen Awarenfunde des 19. Jahrhunderts). Szolnok Megyei Múzeumok Évkönyve 1982-1983, 81-160.

= F. DAIM: Avars and Avar Archaeology. An Introduction. In: H.-W. Goetz-J. Jarnut-W. Pohl (eds): Regna and Gentes. The Relationship between Late Antique and Early Medieval Peoples and Kingdoms in the Transformation of the Roman World. Leiden-Boston 2003, 463-570.

= F. DAIM: Ozora. Reallexikon der Germanischen Altertumskunde 22 (2003) 423-427.

= É. GARAM: Die münzdatierten Gräber der Awarenzeit. In: F. Daim (Hrsg.): Awarenforschungen Bd. 1. Wien 1992, 135-250.

= É. GARAM: Katalog der awarenzeitlichen Goldgegenstände und der Fundstücke aus den Fürstengräbern im Ungarischen Nationalmuseum. Budapest 1993.

= É. GARAM: A népvándorlás kori gyűjtemény (Die völkerwanderungszeitliche Sammlung). In: L. Pintér (Hrsg.): A 200 éves Magyar Nemzeti Múzeum gyüjteményei. Budapest 2002, 71-91.

$=\mathrm{J}$. HAMPEL: A N. múzeum régiségosztály gyarapodása (Zuwachs der Antikensammlung des N. Museums). Archaeologiai Értesítő 9 (1889) 86-87.

= J. HAMPEL: Emlékbeszéd Rómer Flóris rendes tagról (Denkrede auf das ordentliche Mitglied Flóris Rómer). Budapest 1891.

= J. HAMPEL: Alterthümer des frühen Mittelalters in Ungarn. Bde 1-3. Braunschweig 1905.

$=$ I. DiNNYÉs et al.: Magyarország régészeti topográfiája 5. Pest megye régészeti topográfiája. A budai és szentendrei járás (Die archäologische Topographie Ungarns 5. Die archäologische Topographie des Komitats Pest. Kreis Buda und Szentendre). Budapest 1986.

= P. ProhászKa: Az ozora-tótipusztai avar fejedelmi sírok (Die awarischen Oberschichtsgräber von Ozora-Tótipuszta). Opitz Archaeologica 5. Budapest 2012.

= F. PULSZKY: A magyarországi avar leletekről (Über die awarischen Funde Ungarns). In: Értekezések a történelmi tudományok köréből 3/7. Budapest 1874, 5-12.

= F. PULSZKY: Magyarország archaeologiája I-II. (Die Archäologie Ungarns I-II). Budapest 1897.

= F. RóMER: Az ozorai kincs. Egyveleg 119 (Schatz von Ozora. Potpourri 119). Archaeologiai Értesítő 5 (1871) 292-293.

= F. RÓMER: Kivonat a magy. Tudom. Akadémia archaeologiai bizottsága 1871. november 7-én a m. n. muzeumban tartott XII. rendes ülésének jegyzőkönyvéböl (Auszug aus dem Protokoll der XII. ordentlichen im u. Nationalmuseum gehaltenen Sitzung der Archäologischen Kommission der Ungar. Wiss. Akademie vom 7. November 1871). Archaeologiai Értesítő 5 (1871) 273-275.

= F. RÓMER: XVII. Archaeologiai Értesítő 6 (1872) 137-138.

= F. RÓMER: Egyveleg (Potpourri). Archaeologiai Értesítő 6 (1872) 163-164.

= F. RÓMER: Illustrierter Führer in der Münz- und Altertumsabteilung des Ungarischen NationalMuseums. Budapest 1873.

= M. SCHMAUDER: Szentendre. Reallexikon der Germanischen Altertumskunde 30 (2005) 240-244.

= J. SzEnDREI: Az orsz. Rég. Társulat szeptemberi ülése (Die Septembersitzung der land. arch. Gesellschaft). Archaeologiai Értesítő 8 (1888) 372-379.

${ }^{60}$ Garam 1993, 105. 